\title{
Moving towards online rheumatology education in the era of COVID-19
}

\author{
Sakir Ahmed ${ }^{1}$ (D) $\cdot$ Olena Zimba $^{2}$ (D) Armen Yuri Gasparyan $^{3}$ (D)
}

Received: 17 August 2020 / Revised: 6 September 2020 / Accepted: 12 September 2020 / Published online: 17 September 2020

(C) International League of Associations for Rheumatology (ILAR) 2020

\begin{abstract}
The coronavirus disease-2019 (COVID-19) pandemic has unsettled conventional medical education, hastening a switch to digital platforms and open-access publishing. Rheumatology is a fast evolving academic discipline that stands to gain by this switch. Most rheumatology textbooks are now available in digital formats, and these are complemented with live updating educational hubs such as UpToDate and ClinicalKey. Emerging topics of COVID-19 on these proprietary platforms are now freely available to all specialists. Social media channels, particularly Twitter, are becoming major players in the era of COVID-19 by offering online journal clubs, enabling fast dissemination of influential articles, and facilitating interactive education. Indexed rheumatology journals, in turn, aid online education by opening access to recommendations and other materials that are rapidly changing research and practice worldwide. Research peer review additionally offers learning experience to novice and seasoned researchers and authors. Global rheumatology societies have online learning resources, which are changing their format and geographic reach to meet the changing needs in the times of pandemic. While online teaching lacks emotional connections between mentors and mentees, switch to a more interactive format of education and regular contacts may partly solve the issue. Rheumatologists can take the lead in these challenging times and contribute more to online scholarly activities which are aimed to maintain and enrich education.
\end{abstract}

Key Points

- Disparities in rheumatology education are likely to be widened during the COVID-19 pandemic.

- Barriers to rheumatology education include limited number of instructors and their limited experience in online teaching.

- Online textbooks, didactic materials of indexed rheumatology journals, and frequently updated online educational hubs such as UpToDate serve as a foundation of online rheumatology education.

- Online rheumatology education is enriched by peer review and social media activities, which are becoming major players in the time of the COVID-19 pandemic.

Keywords COVID-19 $\cdot$ E-learning $\cdot$ Medical education $\cdot$ Rheumatology $\cdot$ Social media

\section{Introduction}

During the First World War, a piece in The Lancet had focused on Huxley's concept of education [1]. Huxley had said

Armen Yuri Gasparyan

a.gasparyan@gmail.com

Sakir Ahmed

sakir005@gmail.com

Olena Zimba

zimbaolena@gmail.com that the primary aim of education should be to give the possessor a chance to be happy and useful in their generation. The unnamed author or authors of the piece lamented that the medical graduates were not exposed to adequate educational

1 Department of Clinical Immunology \& Rheumatology, Kalinga Institute of Medical Sciences (KIMS), KIIT University, Bhubaneswar 751024, India

2 Department of Internal Medicine No. 2, Danylo Halytsky Lviv National Medical University, Lviv, Ukraine

3 Departments of Rheumatology and Research and Development, Russells Hall Hospital, Dudley Group NHS Foundation Trust (Teaching Trust of the University of Birmingham, UK), Pensnett Road, Dudley, West Midlands DY1 2HQ, UK 
facilities as advocated by Huxley's wisdom. It was pointed out that in certain parts of the UK, scientific training was still hard to come by. More than a hundred years have passed, and the situation is grim again. The current coronavirus disease-2019 (COVID-19) pandemic has led to a significant upheaval to all aspects of society including medical education. Even before the pandemic, disparities existed in healthcare systems worldwide, including rheumatology education [2]. These may be widened as the virus erodes through the already weakened health infrastructure, impacting face-to-face education, and the maintaining of clinical skills by practising $[3,4]$.

By mid-August 2020, the global number of COVID-19 cases has crossed 21 million, with the highest number in the USA (5.5 million crossed), Brazil (3.3 million crossed), and India (2.5 million) [5]. While the curve seems to be flattening for the USA and Brazil, it is still rising in many other countries. Europe is seeing a resurgence of cases, and the second wave of spread is anticipated. Rheumatology education across the globe has been disrupted. Cancellation of face-to-face educational meetings and conferences and trainee redeployment and postponement of examinations have been seen across the world [4, 6, 7]. Rheumatology training hours for undergraduates are limited, but such educational activities often induce a choice to take up rheumatology [8]. Due to the COVID-19 pandemic, basic rheumatology training can be affected unless corrective measures are taken. It should be also kept in mind that many countries attract a large number of medical students and postgraduates from India where the number of aspirants for medical education greatly outnumbers the available seats [9]. The pandemic can halt Indian graduates from attending classes in various medical universities abroad. Even two decades back, it was recognised that with the availability of the worldwide web and extensive handheld electronic devices, it was only a matter of time before medical education shifts to virtual platforms [10]. The pandemic has hastened the evolution. Although the mainstay of medical education is practice-based, COVID-19 has forced medical students worldwide to continue their studies online [11]. Residency programmes in New York have been changed to take into account large patient numbers with a higher proportion of critical illness [12]. Care has been taken so that education is not compromised by using virtual casebased conferences. However, is such an approach viable for countries where health infrastructure is currently under tremendous pressure? There are questions of feasibility and acceptance. As a prime example, medical education in India has been following practices established in Britain, with a recent shift to competency-based training [13]. Rheumatology patients in India had accepted teleconsultation based on the commonly available WhatsApp platform after the onset of COVID-19 [14]. But rheumatology education maybe a different cup of tea altogether. Students from non-Anglophone countries may tend to be less vocal, and thus, there is a need to address cultural needs while designing medical curriculum [15].
This article aims to overview the role of online resources for rheumatology education in the era of COVID-19.

\section{Current barriers to knowledge in rheumatology}

The current number of mentors in rheumatology is limited. Most resource-constrained countries have an enormous load of rheumatology patients and a vastly derisory number of trained rheumatologists [16-18]. Some countries like Korea and Iran have done well recently in the field of rheumatology education $[19,20]$. While countries like Mexico still face acute shortage of rheumatologists, others like Liberia have practically negligible trained rheumatologists $[21,22]$. Thus, there are disparities between regions. While Europe may have a good number of rheumatologists, there is still a felt need for postgraduate level education for various other health professionals associated with rheumatology [23]. Additionally, many newly independent states, such as Ukraine, have developed rheumatology as an academic discipline in the last couple of decades [24]. After gaining independence in 1991, Ukrainian rheumatology has gradually progressed with increasing participation in global rheumatology meetings and representation in indexed rheumatology journals. Like many large countries, Ukraine has a low rheumatologist to patient ratio. The specialisation programme in Ukraine takes 3 months, compared with a median of 24 months in other European countries. Also, the number of junior specialists is limited as compared with senior rheumatologists. The Ukrainian case scenario is an example where properly organised online courses may augment and enrich rheumatology education. Three attributes are required to transcend these existing barriers: flexibility, innovation, and safety [25]. The flexibility should emanate across strata from accreditation bodies to hospital governing bodies, academic faculty, and learners. Innovation is a must in building virtual platforms for teaching. And safety, both physical and mental, should set the framework.

\section{Textbooks and online didactic resources}

Some examples of the globally recognised rheumatology textbooks for trainees are Kelley and Firestein's Textbook of Rheumatology, Oxford Textbook of Rheumatology, Current Diagnosis and Treatment in Rheumatology, Rheumatic Diseases Clinics of North America, and European League Against Rheumatism (EULAR) Textbook on Rheumatic Diseases. These books are adapted for various online formats compatible with most computer programmes. Busy rheumatology residents may also prefer purely Internet-based proprietary resources of large publishers, such as UpToDate 
(Wolters Kluwer) and ClinicalKey (Elsevier) [26, 27]. Online resources like UpToDate have changed the face of medicine. Residents and attending physicians are comfortable with searching UpToDate and retrieving validated evidence syntheses [28]. Physicians relying on UpToDate are less prone to diagnostic errors [29]. This is a portable resource that can aid even during clinical rounds [30]. An evaluation of the evidence presented in UpToDate points to the fact that less than $1 \%$ of the recommendations can be inappropriate [31]. ClinicalKey contains various updated guidelines, videos, and images. It also includes collections of online books and journals. The search feature of ClinicalKey also queries the MEDLINE database [32]. Although the authenticity of data in Wikipedia seems less secure, this online encyclopaedia may be non-inferior to UpToDate in specific scenarios [33]. All these online resources are frequently updated. Many, if not most, include algorithms for approaching patients with different suspected conditions. Importantly, recently drafted and regularly updated COVID-19 items are freely available on UpToDate and ClinicalKey. Many established rheumatology journals have educational sections to carter to the needs of ongoing research fellows and clinicians. EULAR and American College of Rheumatology (ACR) recommendations on various clinical conditions and diagnostic procedures are perhaps the most influential sources for trainees and specialists. Clinical updates, images, and case-based reviews, which are frequently published and promoted on social media by Clinical Rheumatology, may also enrich and diversify materials available to rheumatology trainees. To respond to the challenges posed by the pandemic, many didactic articles on COVID-19 have been published by rheumatology journals with subsequent archiving by PubMed Central.

\section{Social media for rheumatology education}

Social media offers various channels to aid online education and dissemination of evidence on rapidly changing subjects, particularly on COVID-19 prevention and treatment modalities [34]. Nowadays, \#MedEd and \#MedTwitter are widely recognised hashtags, and many scholars are embracing powerful microblogging platforms such as Twitter for sharing their comments and arranging online journal clubs [35]. Twitter has emerged as a powerful influencer regarding dissemination of published articles [36]. Twitter journal clubs are growing in popularity; the most well-known in the field of rheumatology are @ RheumJC and @EULAR JC. The faceto-face discussions can percolate outside the conference halls on to Twitter and reach audiences across the globe, making the traditional conference genuinely global. This year has seen most rheumatology conferences, including the EULAR and the ACR annual meetings, going virtual. Thus, it is expected that Twitter will play a significant role in the discussions and dissemination of educational content of these conferences. Additional examples of Twitter hashtags for rheumatologists to follow are \#FOAMed, \#RheumTwitter, \#CBME (competency-based medical education), \#SoMeDocs (doctors on social media), and \#AcademicTwitter [37]. The next popular online platform is YouTube where variable quality audio and video materials are available for rheumatology trainees and specialists. YouTube offers a variety of graphical materials on most rheumatology topics, exemplified by videos on tumour necrosis factor inhibitors and on secukinumab [38, 39]. Variable quality videos are increasingly posted in the time of the pandemic [40]. Thus, all such materials require curating by experts. Importantly, YouTube can serve as a platform for live streaming educational meetings and engaging numerous viewers in interactive education [41]. Similar functionality is also offered by Facebook [42]. A landmark EULAR survey among young rheumatologists, academics, and basic scientists $(n=233)$ has revealed that around $50 \%$ were using various social media platforms for rheumatology clinical and research updates [43]. In another survey among rheumatologists and allied specialists $(n=111)$, about $50 \%$ of respondents wanted to follow their favourite rheumatology journals on Facebook and Twitter and preferred images and videos for learning [44]. Complementary social media sites can be Instagram and Pinterest [37]. Many specialists have a professional presence on Instagram, with dermatologists benefiting a lot from highly educational images posted on this platform [45]. Pinterest can also help disseminate visually relevant content related to skin and radiology [46]. ResearchGate, Academia.edu, Mendeley, and some other multifunctional online platforms can also be employed for publicly sharing research and ideas and finding mentors with impressive scholarly profiles [47]. Establishing special interest groups on such online platforms can complement the education process that is interrupted due to the pandemic. The shortcomings of online education can be partially overcome by engaging skilled, ethical specialists aware of misinformation spread on social media [48].

\section{Peer review as a part of online rheumatology education}

Many rheumatologists with widely visible publications and impressive online profiles are often invited to act as peer reviewers. The list of the most active rheumatologists (more than 1550) is now available on the Publons reviewer crediting platform, which is a part of Clarivate Analytics [49]. The reviewers may find the manuscript evaluation process professionally and intellectually enriching. It can contribute to updating their knowledge across various rheumatology and allied fields. Additionally, reviewers with access to Web of Science and Scopus may practice with comprehensive searches and provide evidence-based, timely comments 
contributing to the science growth $[50,51]$. The EMerging EULAR NETwork (EMEUNET) has an exemplary online programme for mentoring ongoing research fellows how to review for top journals, filling a void in rheumatology education [52]. The gained reviewer accomplishments can be listed on Publons, honouring the best contributors by certificates of excellence and medals [53].

\section{Role of rheumatology societies}

Several large professional associations have commitments towards furthering and innovating rheumatology education. Their exemplary online resources and programmes are summarised in Table 1.

Young rheumatologist groups such as the EMEUNET are leading from the front in setting up various educational and mentoring programmes [54]. Similarly, the APLAR Young Rheumatologist (AYR) incorporates rheumatologists below 40 years from within the APLAR organisation [55]. Various other rheumatology organisations can take these examples for establishing similar youth wings that will help to promote online rheumatology education.

\section{Drawbacks of online education}

A meta-analysis has found online medical education noninferior versus alternative methods [56]. A recent US-based survey has revealed that the COVID-19 pandemic resulted in a massive shift of education in physical medicine and rehabilitation to virtual didactics, paralleled with the adaptation of patient care to telehealth [57]. Although there is no evidence whatsoever to guide the transformation, the current crisis has resulted in delivering education in occupational therapy online-only [58].

Nonetheless, evidence on gained practical skills, self-efficacy, and trainee satisfaction is still missing. With libraries and university campuses closed due to the quarantine, some trainees, particularly in resource-constrained countries, may encounter difficulties with access to online tools and platforms, let alone Internet access [58].

Conducting online classes is a skill that is honed over time [59]. The COVID-19 pandemic has forced a change in a short term that is not sufficient for advancing online teaching skills. While various online tools and access options may ensure knowledge acquisition at undergraduate and graduate levels, gaining various clinical competencies may be jeopardised in the current conditions. Assessment of rheumatology education is largely based on objective structured clinical examinations and direct observation of practical skills [60]. Both assessment approaches may be insufficient during the pandemic due to the need of a clinical simulation scenario or direct contact with
Table 1 Examples of rheumatology societies with online education resources

\begin{tabular}{ll}
\hline Society & Website \\
\hline $\begin{array}{l}\text { European League } \\
\text { Against }\end{array}$ & https://esor.eular.org/ \\
Rheumatism & \\
(EULAR) &
\end{tabular}

EMerging EULAR https://emeunet.eular.org
NETwork
(EMEUNET)
American College https://www.rheumatology. of Rheumatology org (ACR)

\begin{tabular}{|c|c|c|}
\hline $\begin{array}{l}\text { Pan American } \\
\text { League of } \\
\text { Associations for } \\
\text { Rheumatology } \\
\text { (PANLAR) }\end{array}$ & $\begin{array}{l}\text { http://en.panlar. } \\
\text { org/panlar-edu/recursos }\end{array}$ & $\begin{array}{l}\text { - PANLAR EDU } \\
\text { resources, } \\
\text { including the } \\
\text { social media } \\
\text { primer }\end{array}$ \\
\hline $\begin{array}{l}\text { Asia-Pacific } \\
\text { League of } \\
\text { Associations in } \\
\text { Rheumatology } \\
\text { (APLAR) }\end{array}$ & $\begin{array}{l}\text { https://www.aplar. } \\
\text { org/education/ }\end{array}$ & $\begin{array}{l}\text { - Rheumatology } \\
\text { nurses training } \\
\text { modules } \\
\text { - Fellowships }\end{array}$ \\
\hline $\begin{array}{l}\text { British Society for } \\
\text { Rheumatology } \\
\text { (BSR) }\end{array}$ & $\begin{array}{l}\text { https://rheumatologylearning. } \\
\text { com/ }\end{array}$ & $\begin{array}{l}\text { - Interactive case } \\
\text { modules } \\
\text { - Recorded events } \\
\text { and lectures } \\
\text { (continuing } \\
\text { medical } \\
\text { education) }\end{array}$ \\
\hline $\begin{array}{l}\text { Indian } \\
\text { Rheumatology } \\
\text { Association }\end{array}$ & $\begin{array}{l}\text { https://www. } \\
\text { indianrheumatology.org }\end{array}$ & $\begin{array}{l}\text { - Webinar series } \\
\text { and weekly } \\
\text { educational } \\
\text { podcasts } \\
\text { - Summaries of } \\
\text { current research } \\
\text { in } 3 \text { sections: } \\
\text { basic science, } \\
\text { clinical sciences, } \\
\text { and manuscripts } \\
\text { from India } \\
\text { - Image bank }\end{array}$ \\
\hline
\end{tabular}


a patient. At the same time, rheumatology trainees may improve their competence in ultrasound and other imaging techniques, which are prioritised in the process of moving towards distance learning [60].

The impact on mentor-mentee or student-faculty relationships is still unknown. Cultivating a passionate approach to patient care can be overlooked in the online education process. Also, online classes suffer from an apparent lack of emotional connection. Both student and teacher body language provide unspoken feedback that is often processed on a subconscious level. Often shy students approach a teacher after the class that can help build a teacher-student relationship [59]. A virtual platform is devoid of such human touch, and rheumatologists need to formulate strategies to overcome the emerging issues in education.

\section{Emerging strategies}

The EULAR Working Group on Training has identified four core needs [61]. The first is the need for frequent feedback to the trainees. The second is the developing approaches in close proximity to clinical practices. The third regards providing adequate time for quality observation and feedback, while the last is the systematic approach to incorporate teamwork and professionalism in competence assessments. All these four need to be incorporated into a system of online rheumatology education. Online tools that can be employed by educators should include web-based modules, self-assessment tools, social media journal clubs, interactive learning videos, animations of immunological and pathological pathways, and sites for drug targeting. Top journals have successfully adapted such tools like the interactive videos in the New England Journal of Medicine [62] or the Nature group of journals [63]. Rheumatologists managing patients in the era of COVID-19 may benefit a lot from pliable online education curricula and regular updates of bibliographic databases incorporated in the process of scientific reporting. Telemedicine is increasingly accepted across the world [14], and trainees need to be exposed to this as well. After the onset of the pandemic, most healthcare services, including those of the UK, have shifted all elective patient consultations to online mode [64]. Thus, online training should incorporate training on telerheumatology as well. Also, in countries with limited number of rheumatologists, it makes sense to train allied specialists online too. Such a model had been successfully attempted in Pakistan that has less than 100 trained rheumatologists [65].

\section{Conclusion}

There have been suggestions to apply Gandhian philosophy to manage the situation arising out of the pandemic [66].
"Gandhi always has an answer". Gandhi's talisman was to think of the poorest and the most helpless face one could recall and ruminate how our current actions would benefit that soul. Online rheumatology education has the potential to reach the furthest doctor or healthcare provider in every nook and corner of the world provided there is a critical mass of online users with adequate literacy and advanced access. By increasing rheumatology knowledge and awareness, the quality of life of the underprivileged can be improved. The patient in the periphery may not have access to telemedicine, but if her/his doctor (general practitioner and rheumatologist) has, that may go a long way in alleviating her/his distress. Doctors offered well-established online courses from large rheumatology associations that can be tailored to their changing needs [67]. Subsidising and offering these courses freely to doctors from resource-constrained countries may help achieve a global effect and save countless lives.

The COVID-19 pandemic has unveiled a new role for the rheumatologist [68]. Now the rheumatologist has to be able to integrate immunology with disease pathogenesis, infectious agents, rehabilitation, public health, and epidemiology [69]. The knowledge required for modulating the immune system can no longer be confined to autoimmune diseases but also incorporate emerging and prevalent infectious diseases. The rheumatologists can only expand their horizons via networking with and learning from the experts with various professional backgrounds [70]. Despite some technical limitations and accessibility issues, online rheumatology education has the potential to spread the joy of learning as well as expose potentially brilliant minds to the cutting edge rheumatology. Like molecular targeted therapies in rheumatology, the rheumatologist needs to implement targeted online teaching for various macro- and micro-goals. A teaching-to-target paradigm shift is required in online education, promoting self-development, inculcating pragmatic competencies, and furthering scientific curiosity. Thus, it can fulfil Huxley's dream of genuine education and also satisfy Gandhi's relentless striving for Swaraj (self-rule and self-sufficiency).

Authors' contributions Conceptualisation: Ahmed S, Gasparyan AY, and Zimba O. Methodology: Ahmed S and Zimba O. Writing (original draft): Ahmed S and Gasparyan AY. Writing (review and editing): Ahmed S, Zimba O, and Gasparyan AY. All the authors have approved the final manuscript and take full responsibility for the integrity of the data and the contents of the manuscript.

\section{Compliance with ethical standards}

Disclosures None

Disclaimer All views and opinions expressed in this article are those of the authors and do not necessarily reflect the official policy or position of any institution or association. 


\section{References}

1. [No authors] 1917 The future of medical education. Lancet 190(4905):351-352. doi:10.1016/S0140-736(01)52136-4

2. Sandhu VK, Hojjati M, Blanco I (2020) Healthcare disparities in rheumatology: the role of education at a global level. Clin Rheumatol 39(3):659-666. https://doi.org/10.1007/s10067-01904777-x

3. Ferrel MN, Ryan JJ (2020) The impact of COVID-19 on medical education. Cureus 12(3):e7492. https://doi.org/10.7759/cureus. 7492

4. Akintayo RO, Akpabio A, Kalla A, Dey D, Migowa A, Olaosebikan H, Bahiri R, el Miedany Y, Hadef D, Hamdi W, Oyoo O, Slimani S, Yerima A, Taha Y, Adebajo A, Adelowo O, Tikly M, Ghozlani I, Abdelghani KB, Fouad NA, Mosad D, el Mikkawy D, Abu-Zaid MH, Abdel-Magied RA (2020) COVID19 and the practice of rheumatology in Africa: big changes to services from the shockwave of a pandemic. Ann Rheum Dis Published online July 1, 2020. doi:https://doi.org/10.1136/ annrheumdis-2020-218273

5. WHO Coronavirus Disease (COVID-19) Dashboard. Accessed August 14, 2020. https://covid19.who.int

6. Cai K, He J, Wong PK, Manolios N (2020) The impact of COVID19 on rheumatology clinical practice and university teaching in Sydney, Australia. Eur J Rheumatol 7(Suppl 2):S91-S93. https:// doi.org/10.5152/eurjrheum.2020.20060

7. Liang ZC, Ooi SBS, Wang W (2020) Pandemics and their impact on medical training: lessons from Singapore. Acad Med 95(9): 1359-1361. https://doi.org/10.1097/ACM.0000000000003441

8. Wittoek R, Mielants H (2017) To be or not to be rheumatologist: survey among Belgian medical students and internal medicine trainees: what do certified rheumatologists think about the current rheumatology training program? Clin Rheumatol 36(12):28052812. https://doi.org/10.1007/s10067-017-3673-y

9. Anjali S, Sanjay Z, Bipin B (2016) India's foreign medical graduates: an opportunity to correct India's physician shortage. Educ Health (Abingdon) 29(1):42-46. https://doi.org/10.4103/13576283.178932

10. Ward JP, Gordon J, Field MJ, Lehmann HP (2001) Communication and information technology in medical education. Lancet 357(9258):792-796. https://doi.org/10.1016/S0140-6736(00) 04173-8

11. Gill D, Whitehead C, Wondimagegn D (2020) Challenges to medical education at a time of physical distancing. Lancet 396(10244): 77-79. https://doi.org/10.1016/S0140-6736(20)31368-4

12. Manson DK, Shen S, Lavelle MP, et al (2020) Reorganizing a medicine residency program in response to the COVID-19 pandemic in New York. Acad Med. Published online June 15, 2020. doi: https://doi.org/10.1097/ACM.0000000000003548

13. Rege N (2020) Towards competency-based learning in medical education: building evidence in India. J Postgrad Med 66(1):910. https://doi.org/10.4103/jpgm.JPGM_749_19

14. Shenoy P, Ahmed S, Paul A, Skaria TG, Joby J, Alias B (2020) Switching to teleconsultation for rheumatology in the wake of the COVID-19 pandemic: feasibility and patient response in India. Clin Rheumatol 39(9):2757-2762. https://doi.org/10.1007/s10067-02005200-6

15. Sharma N, Lau C-S, Doherty I, Harbutt D (2014) Medical school pedagogy should be culture-dependent. Acad Med 89(2):194. https://doi.org/10.1097/ACM.0000000000000118

16. Handa R (2015) Rheumatology in India-quo vadis? Nat Rev Rheumatol 11(3):183-188. https://doi.org/10.1038/nrrheum.2014. 182

17. Misra DP, Agarwal V, Negi VS (2016) Rheumatology in India: a bird's eye view on organization, epidemiology, training programs and publications. J Korean Med Sci 31(7):1013-1019. https://doi. org/10.3346/jkms.2016.31.7.1013

18. Georgiev T, Stoilov R (2019) Bulgarian rheumatology: science and practice in a cost-constrained environment. Rheumatol Int 39(3): 417-429. https://doi.org/10.1007/s00296-018-4202-2

19. Khabbazi A, Soroosh M (2019) Rheumatology training and research in Iran. Rheumatol Int 39(8):1307-1319. https://doi.org/10. 1007/s00296-019-04325-5

20. Kim H-Y, Song Y-W (2016) The dynamic evolution of rheumatology in Korea. Nat Rev Rheumatol 12(3):183-189. https://doi.org/ 10.1038/nrrheum.2015.165

21. Pineda C, Sandoval H, Fraga-Mouret A (2019) Mexican rheumatology: where do we stand? Rheumatol Int 39(4):585-593. https:// doi.org/10.1007/s00296-018-4198-7

22. Lewandowski LB, Schiffenbauer A, Mican JM et al (2020) Rheumatology capacity building: implementing a rheumatology curriculum for Liberian health-care providers in 2016. Clin Rheumatol 39(3):689-696. https://doi.org/10.1007/s10067-01904817-6

23. Vliet Vlieland TPM, van den Ende CHM, Alliot-Launois F, Beauvais C, Gobbo M, Iagnocco A, Lundberg IE, MunueraMartínez PV, Opava CH, Prior Y, Redmond A, Smucrova H, Wiek D (2016) Educational needs of health professionals working in rheumatology in Europe. RMD Open 2(2):e000337. https://doi. org/10.1136/rmdopen-2016-000337

24. Doskaliuk B, Zimba O, Yatsyshyn R, Kovalenko V (2020) Rheumatology in Ukraine. Rheumatol Int 40(2):175-182. https:// doi.org/10.1007/s00296-019-04504-4

25. Koumpouras F, Helfgott S (2020) Stand together and deliver: challenges and opportunities for rheumatology education during the COVID-19 pandemic. Arthritis Rheum 72(7):1064-1066. https:// doi.org/10.1002/art.41278

26. De Leo G, LeRouge C, Ceriani C, Niederman F (2006) Websites most frequently used by physician for gathering medical information. AMIA Ann Symp Proc 2006:902

27. Johnson E, Emani VK, Ren J (2016) Breadth of coverage, ease of use, and quality of mobile point-of-care tool information summaries: an evaluation. JMIR Mhealth Uhealth 4(4):e117. https://doi. org/10.2196/mhealth.6189

28. Thiele RH, Poiro NC, Scalzo DC, Nemergut EC (2010) Speed, accuracy, and confidence in Google, Ovid, PubMed, and UpToDate: results of a randomised trial. Postgrad Med J 86(1018):459-465. https://doi.org/10.1136/pgmj.2010.098053

29. Shimizu T, Nemoto T, Tokuda Y (2018) Effectiveness of a clinical knowledge support system for reducing diagnostic errors in outpatient care in Japan: a retrospective study. Int J Med Inform 109:1-4. https://doi.org/10.1016/j.ijmedinf.2017.09.010

30. Phua J, See KC, Khalizah HJ, Low SP, Lim TK (2012) Utility of the electronic information resource UpToDate for clinical decisionmaking at bedside rounds. Singap Med J 53(2):116-120

31. Agoritsas T, Merglen A, Heen AF, Kristiansen A, Neumann I, Brito JP, Brignardello-Petersen R, Alexander PE, Rind DM, Vandvik PO, Guyatt GH (2017) UpToDate adherence to GRADE criteria for strong recommendations: an analytical survey. BMJ Open 7(11):e018593. https://doi.org/10.1136/bmjopen-2017-018593

32. Huslig MA, Vardell E (2015) ClinicalKey 2.0: upgrades in a pointof-care search engine. Med Ref Serv Q 34(3):343-352. https://doi. org $/ 10.1080 / 02763869.2015 .1052696$

33. Scaffidi MA, Khan R, Wang C, Keren D, Tsui C, Garg A, Brar S, Valoo K, Bonert M, de Wolff JF, Heilman J, Grover SC (2017) Comparison of the impact of Wikipedia, UpToDate, and a Digital textbook on short-term knowledge acquisition among medical students: randomized controlled trial of three web-based resources. JMIR Med Educ 3(2):e20. https://doi.org/10.2196/mededu.8188

34. Gupta L, Gasparyan AY, Misra DP, Agarwal V, Zimba O, Yessirkepov M (2020) Information and misinformation on 
COVID-19: a cross-sectional survey study. J Korean Med Sci 35(27):e256. https://doi.org/10.3346/jkms.2020.35.e256

35. O'Glasser AY, Jaffe RC, Brooks M (2020) To tweet or not to tweet, that is the question. Semin Nephrol 40(3):249-263. https://doi.org/ 10.1016/j.semnephrol.2020.04.003

36. Nikiphorou E, Studenic P, Alunno A, Canavan M, Jani M, Berenbaum F (2018) "Twitterland": a brave new world? Ann Rheum Dis 77(8):1245-1246. https://doi.org/10.1136/ annrheumdis-2017-212273

37. Zimba O, Radchenko O, Strilchuk L (2020) Social media for research, education and practice in rheumatology. Rheumatol Int 40(2):183-190. https://doi.org/10.1007/s00296-019-04493-4

38. Tolu S, Yurdakul OV, Basaran B, Rezvani A (2018) Englishlanguage videos on YouTube as a source of information on selfadminister subcutaneous anti-tumour necrosis factor agent injections. Rheumatol Int 38(7):1285-1292. https://doi.org/10.1007/ s00296-018-4047-8

39. Kocyigit BF, Akaltun MS (2019) Does YouTube provide high quality information? Assessment of secukinumab videos. Rheumatol Int 39(7):1263-1268. https://doi.org/10.1007/s00296019-04322-8

40. Kocyigit BF, Akaltun MS, Sahin AR (2020) YouTube as a source of information on COVID-19 and rheumatic disease link. Clin Rheumatol 39(7):2049-2054. https://doi.org/10.1007/s10067-02005176-3

41. Taylor KA, Machlus KR (2020) Blood and Bone: The quarantine chronicles. Res Pract Thromb Haemost 4(5):727-730. https://doi. org/10.1002/rth2.12394

42. Madrigal E, Mannan R (2020) pathCast: an interactive medical education curriculum that leverages livestreaming on Facebook and YouTube. Acad Med 95(5):744-750. https://doi.org/10.1097/ ACM.0000000000003148

43. Nikiphorou E, Studenic P, Ammitzbøll CG, Canavan M, Jani M, Ospelt C, Berenbaum F, EMEUNET (2017) Social media use among young rheumatologists and basic scientists: results of an international survey by the Emerging EULAR Network (EMEUNET). Ann Rheum Dis 76(4):712-715. https://doi.org/10. 1136/annrheumdis-2016-209718

44. Ahmed S, Gupta (2020) Perception about social media use by rheumatology journals: survey among the attendees of IRACON 2019. Indian J Rheumatol 15(3):171-174. https://doi.org/10.4103/injr. injr 1520

45. Wong XL, Liu RC, Sebaratnam DF (2019) Evolving role of Instagram in \#medicine. Intern Med J 49(10):1329-1332. https:// doi.org/10.1111/imj.14448

46. Kauffman L, Weisberg EM, Fishman EK (2019) What Can Pinterest Do for Radiology? J Digit Imaging 32(6):1062-1070. https://doi.org/10.1007/s10278-019-00248-6

47. Gasparyan AY, Nurmashev B, Yessirkepov M, Endovitskiy DA, Voronov AA, Kitas GD (2017) Researcher and author profiles: opportunities, advantages, and limitations. J Korean Med Sci 32(11):1749-1756. https://doi.org/10.3346/jkms.2017.32.11.1749

48. Ahmed S (2020) Letter to the editor: social media is a double-edged sword in the COVID-19 pandemic. J Korean Med Sci 35(29):e270. https://doi.org/10.3346/jkms.2020.35.e270

49. Publons researcher search. Accessed August 14, 2020. https:// publons.com/researcher/?research_field $=5029 \&$ order_by=num reviews

50. Mehregan M (2019) Ethical reviewers are essential for scholarly journals for timely processing of submissions and avoiding retractions. J Korean Med Sci 34(5):e41. https://doi.org/10.3346/jkms. 2019.34.e41

51. Misra DP, Ravindran V, Agarwal V (2018) Integrity of authorship and peer review practices: challenges and opportunities for improvement. J Korean Med Sci 33(46):e287. https://doi.org/10. 3346/jkms.2018.33.e287
52. Rodríguez-Carrio J, Putrik P, Sepriano A, Moltó A, Nikiphorou E, Gossec L, Kvien TK, Ramiro S (2018) Improving the peer review skills of young rheumatologists and researchers in rheumatology: the EMEUNET peer review mentoring program. RMD Open 4(1): e000619. https://doi.org/10.1136/rmdopen-2017-000619

53. Gasparyan AY, Gerasimov AN, Voronov AA, Kitas GD (2015) Rewarding peer reviewers: maintaining the integrity of science communication. J Korean Med Sci 30(4):360-364. https://doi.org/ 10.3346/jkms.2015.30.4.360

54. Frank-Bertoncelj M, Hatemi G, Ospelt C, Ramiro S, Machado P, Mandl P, Gossec L, Buch MH (2014) Mentoring of young professionals in the field of rheumatology in Europe: results from an EMerging EUlar NETwork (EMEUNET) survey. Clin Exp Rheumatol 32(6):935-941

55. AYR - APLAR. Accessed July 3, 2020. https://www.aplar.org/ayr/

56. Richmond H, Copsey B, Hall AM, Davies D, Lamb SE (2017) A systematic review and meta-analysis of online versus alternative methods for training licensed health care professionals to deliver clinical interventions. BMC Med Educ 17(1):227. https://doi.org/ 10.1186/s12909-017-1047-4

57. Escalon MX, Raum G, Tieppo Francio V, Eubanks JE, VerduzcoGutierrez M (2020) The immediate impact of the coronavirus pandemic and resulting adaptations in physical medicine and rehabilitation medical education and practice. PM R. Online ahead of print. doi: https://doi.org/10.1002/pmrj.12455

58. Gustafsson L (2020) Occupational therapy has gone online: what will remain beyond COVID-19? Aust Occup Ther J 67(3):197198. https://doi.org/10.1111/1440-1630.12672

59. Poe CP (2020) Pedagogy in the time of COVID-19. Croat Med J 61(3):211-212

60. Alunno A, Najm A, Sivera F, Haines C, Falzon L, Ramiro S (2020) Assessment of competences in rheumatology training: results of a systematic literature review to inform EULAR points to consider. RMD Open 6(2):e001330. https://doi.org/10.1136/rmdopen-2020001330

61. Najm A, Alunno A, Sivera F, Ramiro S, Haines C (2020) Working Group on Training in Rheumatology across Europe. Strategies for the assessment of competences during rheumatology training across Europe: results of a qualitative study. RMD Open 6(2). doi:https:// doi.org/10.1136/rmdopen-2020-001183

62. Mueller AA, Vaidya A, Tarter LL, Klein JP, Barkoudah E (2020) Caught in a flare. N Engl J Med 383(7):e48. https://doi.org/10. 1056/NEJMimc2003325

63. Nature Video | Nature. Accessed August 14, 2020. https://www. nature.com/nature/articles?type=nature-video

64. Nune A, Iyengar K, Ahmed A, Sapkota H (2020) Challenges in delivering rheumatology care during COVID-19 pandemic. Clin Rheumatol 39:2817-2821. https://doi.org/10.1007/s10067-02005312-z

65. Khan SEA, Saeed MA, Batool S, Farman S, Ahmad NM, Hasni SA (2020) A rheumatology curriculum in Pakistan for empowering family physicians and fighting disability. Clin Rheumatol 39(3): 681-687. https://doi.org/10.1007/s10067-019-04797-7

66. Bang A (2020) Faced with today's crisis, what would Gandhi do? Lancet 395(10242):e114-e115. https://doi.org/10.1016/S01406736(20)31413-6

67. Al Maini M, Adelowo F, Al Saleh J et al (2015) The global challenges and opportunities in the practice of rheumatology: white paper by the World Forum on Rheumatic and Musculoskeletal Diseases. Clin Rheumatol 34(5):819-829. https://doi.org/10.1007/ s10067-014-2841-6

68. Kernan KF, Canna SW (2020) Should COVID-19 take advice from rheumatologists? Lancet Rheumatol 2(6):e310-e311. https://doi. org/10.1016/S2665-9913(20)30129-6

69. Misra DP, Agarwal V, Gasparyan AY, Zimba O (2020) Rheumatologists' perspective on coronavirus disease 19 
(COVID-19) and potential therapeutic targets. Clin Rheumatol 39(7):2055-2062. https://doi.org/10.1007/s10067-020-05073-9

70. Al Maini M, Al Weshahi Y, Foster HE et al (2020) A global perspective on the challenges and opportunities in learning about rheumatic and musculoskeletal diseases in undergraduate medical education: white paper by the World Forum on Rheumatic and
Musculoskeletal Diseases (WFRMD). Clin Rheumatol 39(3):627642. https://doi.org/10.1007/s10067-019-04544-y

Publisher's note Springer Nature remains neutral with regard to jurisdictional claims in published maps and institutional affiliations. 